\section{Crecimiento Postraumático en víctimas del conflicto armado colombiano: análisis de historias de vida ${ }^{1}$}

Post-traumatic growth among victims of the Colombian armed conflict: Analysis of life histories
Tatiana Milena Morantes Montoya²

tatiana.morantes98@gmail.com

Manuel Beltrán Espitia ${ }^{3}$

det.mbeltran@uniclaretiana.edu.co

https://doi.org/10.22209/rhs.v7n2a01

Recibido: septiembre 30 de 2019.

Aceptado: diciembre 6 de 2019

\section{Resumen}

La presente investigación tuvo como objetivo analizar historias de vida sobre crecimiento postraumático de las víctimas de desplazamiento forzado en El Carmen de Atrato en el departamento del Chocó - Colombia. El estudio se realizó por medio de la metodología cualitativa desde un enfoque descriptivo, en el cual se utilizaron como técnicas la entrevista a profundidad y el análisis interpretativo de la historia de vida como método. En las historias de vida se analizó el crecimiento postraumático, luego de vivir desplazamiento

1 Este artículo es resultado del desarrollo del proyecto de grado para optar al título de Psicología.

2 Fundación Universitaria Claretiana.

3 Docente investigador de la Fundación Universitaria Claretiana. Líder de investigación del grupo de investigación GIPSICLA. forzado. Los cambios de mayor impacto encontrados como resultado de la presente investigación fueron la fortaleza personal, las nuevas posibilidades y la nueva valoración de la vida que hacen referencia al cambio de percepción de sí mismo; también, el cambio en las relaciones interpersonales en las que se observa la mejora en las interacciones sociales. Finalmente, se evidenció el incremento o fortalecimiento en las creencias de los participantes, que denota el crecimiento espiritual de forma moderada.

Palabras claves: Chocó; Colombia; crecimiento postraumático; desplazamiento forzado; historia de vida; víctimas.

\section{Abstract}

This research study aims to analyze life histories connected to post-traumatic growth of victims of forced displacement in El Carmen de Atrato, department of Chocó (Colombia). The study was based on the qualitative methodology using a descriptive approach. The in-depth interview was used as a technique and the interpretative life history analysis was used as a method. In a sample of life histories, post-traumatic growth after forced displacement was analyzed. The changes with the greatest impact found in this research study 
include personal strength, new possibilities and a new assessment of life that attest to a change in self-perception. A change was also observed in interpersonal relationships with improvement in social interactions. Finally, an increase or strengthening in the beliefs of the participants was found, which indicates moderate levels of spiritual growth.

Keywords: Chocó, Colombia, post-traumatic growth, forced displacement, life history, victims.

\section{Introducción}

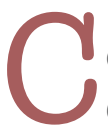
olombia se ha encontrado sumergida en el conflicto armado desde 1965 (Tawse-Smith, 2008). El conflicto colombiano por su duración ha sido caracterizado como uno de los conflictos armados más antiguos del mundo, dejando entrever un contexto social de violencia bajo las diferencias políticas, económicas y sociales entre el Estado Nacional y distintos grupos armados ilegales. Esta estructura y dinámica afectan directa e indirectamente a las personas que sufren los flagelos de una guerra en la que se da la vulneración diaria de los derechos humanos (Contreras, 2003; Obando, Viscaya, y Fernández, 2016; Rojas, 2016).

De acuerdo con los datos del Registro Único de Víctimas (RUV) (2 de Septiembre de 2019a), en Colombia hay 8874110 personas víctimas del conflicto armado de las zonas rurales y urbanas, las cuales han sido afectadas por hechos tales como homicidios, desapariciones forzadas, masacres, secuestros, tortura, desplazamientos forzados, entre otros hechos victimizantes, que atentan contra la seguridad e integridad de los colombianos.
Aunque en Colombia el conflicto armado ha hecho presencia en las diferentes zonas del país, uno de los departamentos más afectados ha sido el Chocó, ocupando el sexto lugar a nivel nacional (Corporación Humanas, 2019). Desde 1980, este departamento ha sido un punto estratégico para el desarrollo de actividades ilegales, lo cual generó la presencia de grupos al margen de la ley y la confrontación de estos con otros grupos armados por el dominio de la economía ilegal y la extensión territorial (Serra-Horhuelin y SchoeIler-Díaz, 2014). Según los datos del RUV (2 de Septiembre de 2019b), el mayor hecho victimizante que se presenta en el departamento es el desplazamiento, con un total de 278018 víctimas registradas lo que representa un $83.7 \%$ en relación a los demás eventos.

Uno de los municipios del departamento del Chocó que se ha visto afectado por el desplazamiento forzado es El Carmen de Atrato. Se encuentra una cifra de 8891 víctimas hasta la fecha según el RUV (2 de Septiembre de 2019b), lo cual representa un $82.6 \%$ en relación con los demás hechos victimizantes que se han presentado en el municipio.

La población de El Carmen de Atrato, debido al desplazamiento forzado, se ha visto obligada a migrar, abandonar o huir del territorio donde se encuentran con el fin de evitar ataques directos o como mecanismo de protección para evitar los hechos violentos por parte de los grupos armados (Jaimes, 2014). El desplazamiento genera cambios en las personas, incide de forma directa en el sustento económico y autosuficiencia. Este hecho fragmenta la dignidad humana, se evidencia en la perdida de la identidad con el territorio. No obstante, y en medio del dolor, el desplazamiento acarrea consigo el surgimiento de 
distintos mecanismos de protección relacionados con el cuidado de integridad, la seguridad y el bienestar individual y colectivo (Ibáñez y Velásquez, 2008).

El desplazamiento forzado genera impacto, pone a prueba la estabilidad personal, familiar y social en las personas que se ven afectadas por este, convirtiéndose en una acontecimiento traumático para estas personas, al generar daños en la identidad ${ }^{4}$ transformación y daño en la autonomía, afectación de la seguridad vital y existencial (Alvarán, García, y Gil, 2009; Barberol y Linley, 2006).

Enfrentarse a un evento traumático es repentino, inesperado y amenazante, obliga a cambios, impactos, y llena de angustia a quien lo experimenta; este puede producir en los individuos crisis existenciales, acompañadas de respuestas físicas (fatiga, tensión muscular); psicológicas (ansiedad, depresión, culpa, ira); consecuencias sociales y visión negativa o positiva del mundo y de sí mismo, trayendo consigo secuelas psicológicas o un trauma luego del evento (Costa y Gil, 2008; Páez, Beristain, Gonzales-Castro, Basabe y de Rivera, 2011; Shakespeare-Finch y Copping, 2006).

El trauma ha sido conceptualizado como una consecuencia a la exposición de un evento abrumador e irremediable que supera a una persona su capacidad de afrontamiento. Por lo tanto, se evidencia que aunque dos o más personas hayan sido expuestas a un mismo acontecimiento no reaccionarán de manera similar, pues existen distintos factores que influyen en la percepción y afrontamiento del suceso

4 Alvarán et al. (2009) lo definen como «el relato biográfico que ha construido el sujeto o la comunidad se trastoca tras el ingreso de situaciones abruptas y adveras que lo confrontan» (p. 322). adverso, tales como experiencias previas, red de apoyo social, las habilidades para enfrentar el evento, predisposiciones genéticas, sistemas de creencias, al igual que los mecanismos de adaptación, entre otros (Cruz, 2012).

Sin embargo, aunque vivir un hecho traumático puede configurar en la mente de las víctimas una visión negativa de sí mismo y del mundo, también puede desencadenar en las personas que sufren un trauma efectos positivos en el ámbito personal y en las relaciones interpersonales; este fenómeno se le conoce como crecimiento postraumático (CPT) (Barberol y Linley, 2006; Páez et al., 2011).

El CPT se entiende como la capacidad que tiene el ser humano de generar cambios positivos en diferentes ámbitos de la vida luego de experimentar un suceso traumático (Tedeschi y Calhoun, 2004 ; Páez, Bilbao y Javaloy, 2008). «El individuo no solo sobrevive y resiste, sino que dicha experiencia produce en él un cambio positivo que le lleva a un estado mejor del que se encontraba antes de ocurrir el evento» (Esparza, Martínez, Leibovich, Campos, y Lobo, 2015, p. 304).

En investigaciones realizadas por Andrades (2016); Bhor (2017); Páez et al. (2008); Tedeschi y Calhoun (1996) se plantean tres dimensiones que experimenta una persona posterior al evento traumático: el cambio en la percepción de sí mismo, el cambio en las relaciones interpersonales y el cambio en la filosofía de vida. Estos indicadores dan cuenta de los cambios positivos que tras afrontar el trauma se producen en la persona.

El cambio en la percepción de sí mismo hace referencia al crecimiento personal, donde se experimenta el desarrollo de confianza, 
fortaleza y seguridad en sí mismo, posibilitando en el ser humano cambio como persona, madurez, adquirir capacidades y habilidades más altas para enfrentarse a nuevas situaciones adversas (Andrades, 2016; Bhor, 2017; Páez et al., 2008; Tedeschi y Calhoun, 1996).

Frente al cambio en las relaciones interpersonales, se genera un fortalecimiento en las relaciones sociales; en este se lleva a cabo una aproximación a familiares y personas más cercanas, se incrementa el servir de forma constructiva a los otros, la participación social, el compartir emocional y la empatía (Andrades, 2016; Bhor, 2017; Páez et al., 2008; Tedeschi y Calhoun, 1996).

Por último, el cambio en la filosofía de vida es definido como las transformaciones radicales que suelen desencadenarse en las ideologías y concepciones que tiene la persona de ver el mundo desde la moral, los valores y la espiritualidad luego de la experiencia traumática. Asimismo, surge la restructuración en la filosofía de vida, creando la idea de solo preocuparse por el aquí y ahora, dando paso a la percepción de nuevas inspiraciones, oportunidades y posibilidades de desarrollo espiritual y personal (Andrades, 2016; Bhor, 2017; Páez et al., 2008; Tedeschi \& Calhoun, 1996).

Teniendo en cuenta el panorama de violencia originada por el conflicto armado, el propósito de la presente investigación estuvo orientado a analizar historias de vida de personas víctimas de desplazamiento forzado residentes del municipio de El Carmen de Atrato - Chocó que evidencian CPT. Para esto, se tuvieron en cuenta tres momentos relevantes en los participantes, el antes, durante y posterior a vivir el suceso traumático, con el fin de poder evidenciar en cada uno el desarrollo de crecimiento postraumático.

\section{Metodología}

La investigación se llevó a cabo en el municipio de El Carmen de Atrato del departamento del Chocó, con personas residentes que fueron víctimas de desplazamiento forzado. El enfoque investigativo es cualitativo (Breu, Guggenbichler, y Wollmann, 2008), lo que permitió describir y comprender las historias de vida de las víctimas de desplazamiento forzado. La técnica empleada fue la entrevista en profundidad (Quecedo y Castaño, 2003), la cual permitió contemplar la experiencia de cada uno de los participantes con referencia al evento o situación adversa que experimentó, y que a su vez le conllevó a desarrollar un CPT.

Para el desarrollo de esta investigación se utilizó como método el análisis interpretativo de historia de vida (Sandoval, 2002), para conocer las dinámicas de vida que tenían los participantes desde tres perspectivas: antes del desplazamiento, el cambio que enfrentaron durante el desplazamiento y, por último, el crecimiento postraumático y la manera en que se desarrolló.

Para el análisis de la información se utilizó el software Atlas TI 7.0, el cual permitió evidenciar los puntos críticos que dieron paso al desarrollo del crecimiento postraumático, configurando las categorías desarrolladas y evidenciando procesos emergentes de significancia psicológica en los participantes. 


\section{Muestra}

El desarrollo de esta investigación estuvo conformado por 12 participantes. El muestreo fue de tipo no estadístico por conveniencia (Otzen y Manterola, 2017). Inicialmente, se aplicó la escala Post-traumatic Growth Inventory de Calhoun y Tedeschi a 50 participantes de la comunidad de El Carmen de Atrato mediante muestreo de bola de nieve (Martínez-Salgado, 2012). Al evaluar los resultados se seleccionaron 12 participantes finales que puntuaron alto en la escala y demostraron mayor crecimiento postraumático.

La presente investigación contempló como criterios de inclusión los siguientes aspectos: ser víctima de desplazamiento forzado, ser residente del municipio del Carmen de
Atrato, y, por último, haber puntuado positivo en la Escala de CPT de Tedeschi y Calhoun en la versión de español editada por Páez et al. (2011). Este instrumento está compuesto por 21 ítems en una escala de Likert de 0 a 5 puntos, donde el valor de cero equivalía a ningún cambio y cinco un cambio muy importante; evaluaba los beneficios y consecuencias positivas percibidas por los participantes (Maldonado, Cova, Bustos, y García, 2014).

La evaluación de la Escala de CPT (ver Tabla 1) se realizó internamente para obtener los resultados frente a la evidencia de crecimiento postraumático, teniendo en cuenta que para verse evidenciado el cambio o crecimiento moderado, se debía tener una puntuación total superior a 72 (Páez et al., 2011).

Tabla 1.Claves de evaluación.

\begin{tabular}{|c|c|c|c|c|c|}
\hline $\begin{array}{c}\text { Mejora en } \\
\text { relaciones } \\
\text { con otros }\end{array}$ & $\begin{array}{c}\text { Nuevas } \\
\text { posibilidades }\end{array}$ & $\begin{array}{c}\text { Fortaleza } \\
\text { personal }\end{array}$ & $\begin{array}{c}\text { Nueva } \\
\text { valoración } \\
\text { de la vida }\end{array}$ & $\begin{array}{c}\text { Crecimiento } \\
\text { espiritual }\end{array}$ & Resultado \\
\hline $\begin{array}{c}6+8+9+15+1 \\
6+20+21\end{array}$ & $\begin{array}{c}3+7+11+ \\
14+17\end{array}$ & $\begin{array}{c}4+10+1 \\
2+19\end{array}$ & $1+2+13$ & $5+18$ & $\begin{array}{c}\text { Puntuaciones totales global } \\
\text { superiores a } 72 \text { muestran un grado } \\
\text { de cambio } 0 \text { crecimiento moderado. }\end{array}$ \\
\hline
\end{tabular}

Fuente: (Páez et al., 2011).

Asimismo, se tuvieron en cuenta los siguientes criterios de exclusión: ser víctima de desplazamiento de otros municipios, ser menor de edad y mayor de 60 años, poseer una discapacidad sensorial e intelectual y haber desarrollado resiliencia (Arias-Gómez, ViIlasís-Keever y Miranda-Novales, 2016). 


\section{Resultados}

La investigación se materializó a partir del diseño de categorías orientadas a la identificación del crecimiento postraumático, en total se situaron tres categorías: previo al evento traumático, durante el evento y crecimiento postraumático. Las categorías fueron establecidas por la importancia de cada periodo de tiempo en la historia de vida de cada uno de los participantes. La primera contempla el análisis de la cotidianidad de las personas antes del evento traumático. La segunda permite evidenciar las situaciones adversas a las que se enfrentaron los participantes debido al suceso traumático. Por último, se logra determinar los cambios que generaron las personas luego del evento adverso y cuáles fueron los más relevantes de acuerdo con el enfoque teórico.
El análisis de las experiencias de los participantes se realizó a partir de códigos y categorías de análisis recopiladas; en cada uno se evidenciará un número extremo izquierdo que hace referencia al número de veces de aparición en el discurso, y el número extremo derecho, la relación que tienen con otras categorías.

\section{Previo al evento traumático}

Como se observa en la Figura 1, los participantes resaltan que existían condiciones que proporcionaban una calidad de vida estable, las cuales generaban tranquilidad en la cotidianidad de sus vidas antes del hecho victimizante. Se asocian los códigos de unión familiar, tranquilidad, autosuficiencia y cultura transgeneracional.

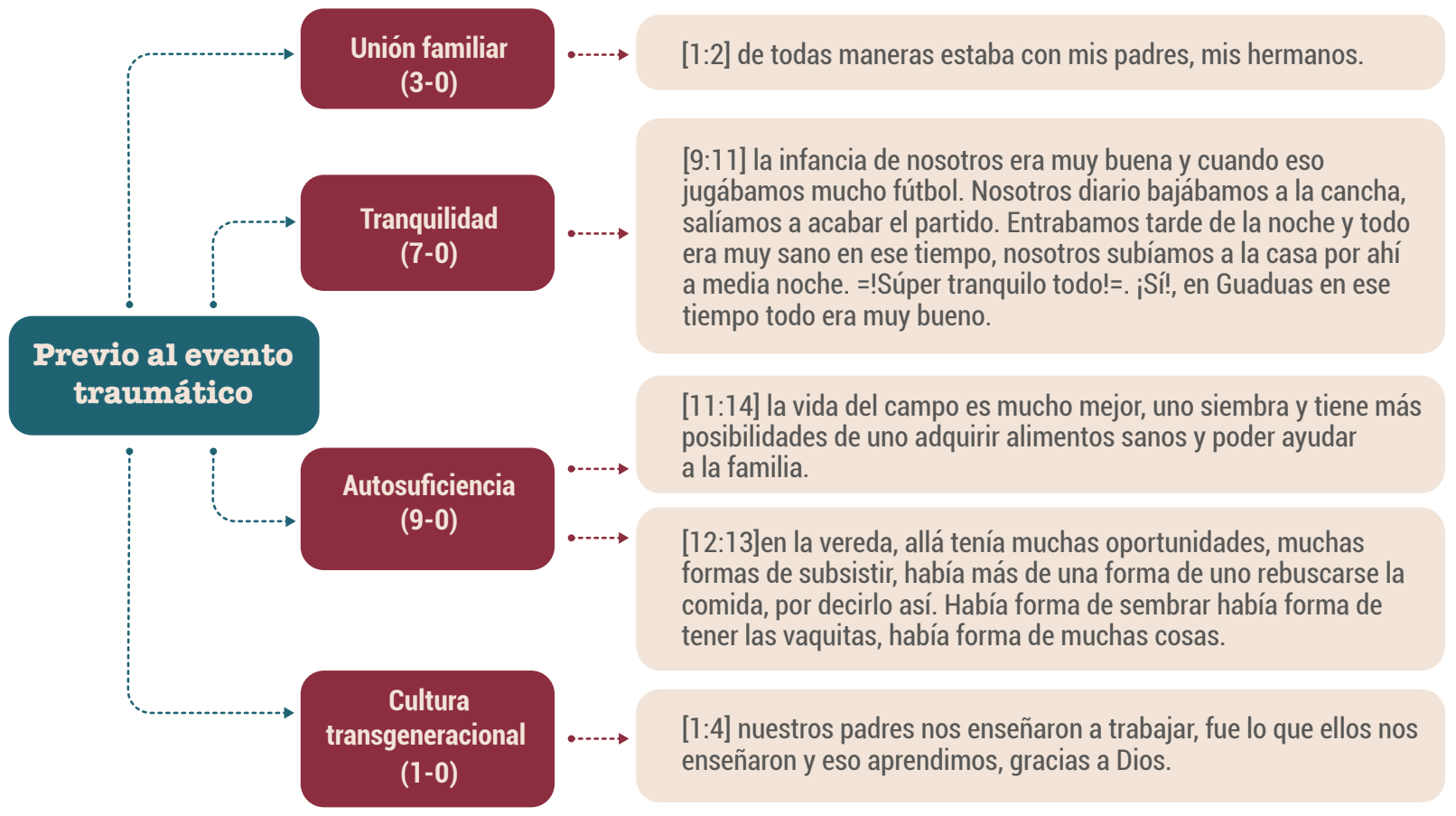

Figura 1. Previo al evento traumático.

Fuente: elaboración propia. 
En el código de unión familiar se plantea que el núcleo familiar era estable, los miembros de la familia conservaban lazos afectivos. Respecto al código de tranquilidad se evidencia que la infancia, adolescencia y adultez fue percibida por los participantes como una experiencia de gran relevancia por las condiciones que eran expuestas en estas etapas y las vivencias en el lugar que residían. En esta época se mantenía la realización de encuentros culturales como juegos, fiestas y acercamiento a otras familias vecinas.

$\mathrm{P}^{5} 12$ : «Muy bien, muy bueno, era lo mejor para nosotros allá, como niños, porque nosotros nos divertíamos allá, jugando, todo era muy sano, muy bueno».

El código de autosuficiencia comprende la autonomía y estabilidad económica que tenían los participantes en las fincas o residencias donde vivían, ya que contaban con recursos naturales o económicos suficientes que posibilitaban un sustento estable, partiendo desde los productos que se producían en sus propias fincas, contaban con ganado vacuno y siembra de diferentes alimentos; se considera que en esa época existían más oportunidades y formas de subsistir, había más independencia laboral y económica. Finalmente, el código de cultura transgeneracional se basa en los saberes ancestrales que transmiten mediante la identidad cultural, haciendo énfasis en la forma de sustentación e independencia laboral.

\section{Durante el evento traumático}

En la Figura 2 (ver en la siguiente página), se caracterizan los factores y condiciones que generaron en los participantes el desplazamiento forzado de residencias o veredas en las que se encontraban en esa época.

5 Los participantes serán nombrados de aquí en adelante con la letra «P». 


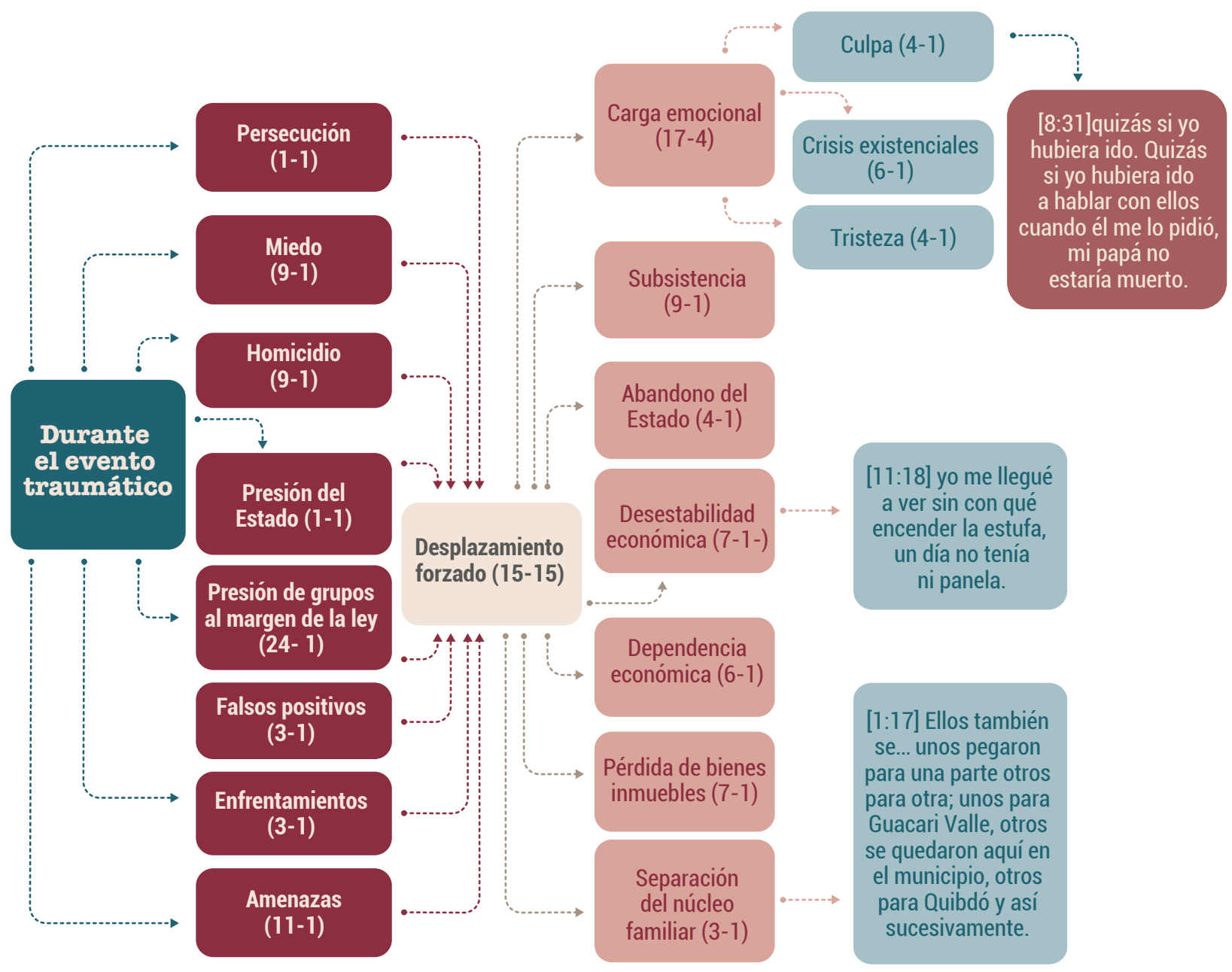

Figura 2. Durante el evento traumático.

Fuente: elaboración propia.

En esta red se establecen los códigos de persecución, miedo, homicidio, presión del Estado, presión de grupos al margen de la ley, falsos positivos, enfrentamiento y amenazas, siendo estos los factores que desencadenaron el desplazamiento forzado. Asimismo, emergen los códigos que dan cuenta de las condiciones de vida ocasionadas por el desplazamiento forzado en los participantes, la subsistencia, abandono del Estado, desestabilidad económica, dependencia económica, pérdida de bienes inmuebles, separación del núcleo familiar y la carga emocional. En este código emergieron crisis existenciales, tristeza y culpa.

Respecto al código de persecución, se plantea que los grupos al margen de la ley generaron presión en el núcleo familiar al querer llevarse uno de los miembros de este. Se presentaron momentos en los cuales las personas abandonaban sus hogares para asentarse en otras zonas, pero seguían siendo amedrentados por los grupos armados, sintiéndose inseguros y amenazados. 
P4: «Esa gente nos perseguía, ¿le digo por qué? Porque perseguían mucho a Maricell, que porque se la iban a llevar. Nosotros corríamos».

En el código miedo se evidencian las prevenciones para velar por su seguridad y la de su núcleo familiar, debido a las acciones que los grupos armados realizaron en contra de personas cercanas o de la misma vereda donde se encontraban. Asimismo, se encuentra la falta de confianza para movilizarse a otras zonas o dentro de la cabecera municipal por temor a vivenciar nuevas agresiones por parte de los grupos armados.

P10: «Uno al principio era muy azarado, uno por donde andaba mandaba un paso y le parecía que ya le iban a dar, o que ya lo iban a coger o que ya cualquier cosa».

Referente al código homicidio, postulan los asesinatos realizados por los grupos al margen de la ley a familiares y gran parte de la población que hizo caso omiso de desalojar las zonas que se habían declarado objetivo militar:

P8: «Yo que piso la puerta de mi casa, cierro la puerta, cuando escucho tres tiros. Después de que escucho esos tiros, escucho otros tiros más. Cuando ahí mismo, al instante, que no pasaron ni diez minutos, cuando al instante, abre la puerta mi hermana, "Dora, Dora, salga que mataron a mi papá, salga". "¡Ay Dios mío! Yo no lo puedo creer, es que yo hace un momentico hablé con él, yo hace un momentico lo dejé allá en la casa, él no es, es que él no es, pero como va a ser él". Yo me acuerdo que yo me asomé y vi a una de esas personas con el arma así de para arriba, corriendo de donde lo mataron a él, corriendo hacia el río, hacía el Puente de Habitad, ya cuando lo habían asesinado, corriendo ya como para escaparse».

Además, en el código presión del Estado, postulan que el Estado tenía conocimiento de los grupos al margen de la ley que estaban vulnerando los derechos de la población que se encontraba ubicada en la vereda de Guaduas y el Siete, sin embargo, de acuerdo con los participantes, estos hicieron caso omiso a ello y no se brindó protección y seguridad previa a la población afectada. También se establece que las fuerzas militares se acercaban con el objetivo de pedirles información de los grupos subversivos que se encontraban en la zona.

En el código presión de grupos al margen de la ley, plantean la presencia de los grupos armados en las comunidades, la exigencia de estos para que fueran informantes y la intimidación al tener acercamientos constantes en sus lugares de residencia y laborales, en los que satisfacían necesidades básicas como prepararse alimentos o descansar el tiempo que desearan, acciones que realizaron con o sin el consentimiento de la población:

P7: «Los actores de la guerrilla querían que nosotros les colaboráramos y nosotros le decíamos que no podíamos, porque no se podía, porque sería involucrarnos en el conflicto. $Y$ entonces nos decían que, si no íbamos a colaborar, teníamos también que echarnos a perder de la región».

Respecto al código de falsos positivos, se evidencia los asesinatos en contra de familiares o personas de la comunidad que se desempeñaban como líderes sociales o en su efecto 
eran campesinos inocentes, los cuales fueron señalados por grupos al margen de la ley como informantes o pertenecientes a otros grupos armados.

P9: «Cuando los mataron hicieron dizque una reunión. Yo no fui, pero dijeron que era dizque por informantes, pero ya al tiempo, ahora que están en esas audiencias. Una vez mi mamá les preguntó que ellos porqué habían matado los muchachos y dijeron dizque un error como tantos de los que habían cometido».

En el código de enfrentamientos, plantean la presencia constante de los grupos al margen de la ley en la comunidad, por lo tanto, se presentaban confrontaciones entre los grupos armados presentes y la comunidad quedaba en medio de este fuego cruzado.

P12: «Cuando entraba el ejército se podía prender, cómo se dice, una guerra entre ellos, como digámoslo pues así. Entonces podía pasar algo y nosotros estando ahí metidos en medio. Una vez sucedió, nosotros vivíamos por ejemplo en la mitad de un río. Y al otro lado del río estaba el ejército y acá al lado de la casa, por estos montes, estaba la guerrilla. Y se prendieron así a fuego cruzado, nosotros en medio de ese fuego cruzado".

Asimismo, el código amenazas comprende la presión que ejercieron los grupos armados sobre los participantes y las personas de la comunidad para que desalojaran las residencias o la comunidad donde estaban ubicados, también la consistencia que se convirtieran en informantes, por lo tanto, quienes hicieran caso omiso serían asesinados.
P1: «Un jefe de esos estaba montado encima de nosotros, que nos teníamos que ir. $Y$ nos tuvimos que ir, por eso nos tuvimos que ir".

Los códigos mencionados expresan los factores que causaron que los participantes tuvieran que desplazarse de forma forzosa de sus localidades, viéndose obligados a reubicarse en otros municipios o zonas vecinas para salvaguardar la vida y la de su familia. Este hecho victimizante generó las condiciones en las que se vieron enfrentados los participantes luego del desplazamiento forzado y los estados emocionales derivados del mismo.

Respecto al código de carga emocional, emergen los códigos de culpa, crisis existenciales y tristeza, estos expresan lo difícil, lamentable y triste que fue para cada uno de los participantes dejar de forma inesperada sus bienes inmuebles, la suspensión de actividades culturales como el pan coger o cultivo y la pérdida de familiares o personas cercanas por los grupos armados. De igual manera, surgieron atribuciones de culpa consigo mismos frente a las acciones que consideraron hubiesen podido evitar ciertos eventos, tales como el asesinato de un miembro de la familia, en el cual no llevaron a cabo ningún tipo de comportamiento que los salvaguardara por el miedo o falta de conocimiento de las amenazas de los grupos armados.

P2: «Ese suceso, muy triste porque, imagínese matarle el hermano y el cuñado el mismo día. Eso fue muy duro, nosotros ese día estábamos celebrando un cumpleaños de un niño, cuando no oímos sino el tiroteo que fueron como a cada uno de a 14 tiros que les dieron». 
P8: «Yo le di comida en mi casa, fue la última comida que se comió allá. Se la comió con tanto gusto, se comió la sopita de pastas que yo le había hecho, una comida muy especial. De yo haber sabido que esa era la última comida que él se iba a comer ese día, pues, mejor dicho, le había guisado un pavo o que se yo que le hubiera hecho».

En el código de subsistencia, se devela las nuevas actividades que decidieron emprender los participantes para poder tener un sustento económico, tales como la búsqueda activa de cualquier labor legal en otras zonas o municipios que les permitiera generar algún tipo de ingreso, aunque fuese pequeño, con el fin de poder satisfacer sus necesidades básicas y las de su familia.

P6: «Mi papá y mi mamá tuvieron que empezar de cero. Mi papá siempre salía por ahí con el cuñado de nosotros, el esposo de Gladys. Él vendía en los semáforos y se lo llevaba a vender cositas en los semáforos a mi papá».

De igual manera, en el código de abandono del Estado, plantean el desinterés y poca presencia del Estado para brindar protección, seguridad y ayuda humanitaria a los participantes y la comunidad en general que fueron vulnerados por los hechos victimizantes.

P12: «Yo miro mucha injusticia, o sea que hay muchas cosas que se debieron haber prevenido y que ningún ente gubernamental o no gubernamental no hizo nada. No tuvimos apoyo. Y fuera de eso, ellos conocían la situación que estaban viviendo en Guaduas, y no hicieron nada, se hubiera podido prevenir».
Referente al código de desestabilidad económica, comprende la falta de recursos y autodeterminación que tuvieron los participantes al ubicarse en nuevas zonas o municipios, lo cual los privaba de tener una vivienda o una alimentación adecuada, la migración a otras veredas en busca de oportunidades para subsistir y los diferentes prestamos realizados para poder satisfacer algunas necesidades.

P11: «Yo me llegué a ver sin con qué encender la estufa, y un día no tenía ni panela».

También se evidenciaron señalamientos y exclusión por gran parte de la población carmeleña hacia los participantes y personas que fueron desplazadas, etiquetándolos como colaboradores o pertenecientes a alguno de los grupos armados, por lo cual evitaban algún tipo de relación laboral, por lo tanto, encontrar nuevas oportunidades fue difícil al enfrentarse con ese estereotipo social.

Referente al código de dependencia económica, los participantes postulan el apoyo que recibieron de parte de familiares, casas de hogar o personas conocidas. Estos les brindaron un espacio en sus viviendas junto con su núcleo familiar mientras podían encontrar una manera de generar ingresos económicos para independizarse nuevamente:

P7: «Mi hermano Julio fue él como que se hizo cargo de todos. Él era el que trabajaba, y llevaba la comida, pagaba los servicios y todo allá».

En el código de pérdida de bienes inmuebles, comprende la falta de oportunidad que se tuvo para transportar sus pertenencias al verse obligados a desalojar la zona de forma 
repentina, también los daños de las viviendas, ganados, gallinas, etc., ocasionados por los grupos armados, y el hurto de alimentos y objetos que pertenecían a los participantes.

P3: «Nos quemaron las casas, las dos casas».

P12: «Él perdió casi que todo. Perdió las gallinas. Todo, todo, todo, perdimos todo. Los corotos, lo que pudimos sacar de corotos fue muy poquito. Lo otro lo quemaron los paramilitares cuando entraron».

Por otro lado, respecto al código de separación del núcleo familiar, plantean las estrategias que utilizaron los miembros para subsistir, tomando la decisión de dividirse y ubicarse en diferentes municipios donde tenían familiares o encontraron oportunidades laborales para empezar a generar ingresos económicos.
P7: «Ellos también se desplazaron, unos pegaron para una parte, otros para otra. Unos para Guacari Valle, otros se quedaron aquí en el municipio, otros para Quibdó y así sucesivamente».

\section{Crecimiento postraumático}

Finalmente, emerge el tercer momento (Figura 3, ver en la siguiente página), se evidencian los cambios positivos que desarrollaron los participantes luego del desplazamiento forzado. En este diagrama se establecen las categorías de cambio en la percepción de sí mismo, en la cual aparece la subcategoría de fortaleza personal, la categoría de cambio en las relaciones interpersonales, donde emerge la subcategoría de mejora en relaciones con otros, la categoría de cambio en la filosofía de vida, en la cual se manifiestan las subcategorías de nuevas posibilidades, nueva valoración de la vida y crecimiento espiritual. 


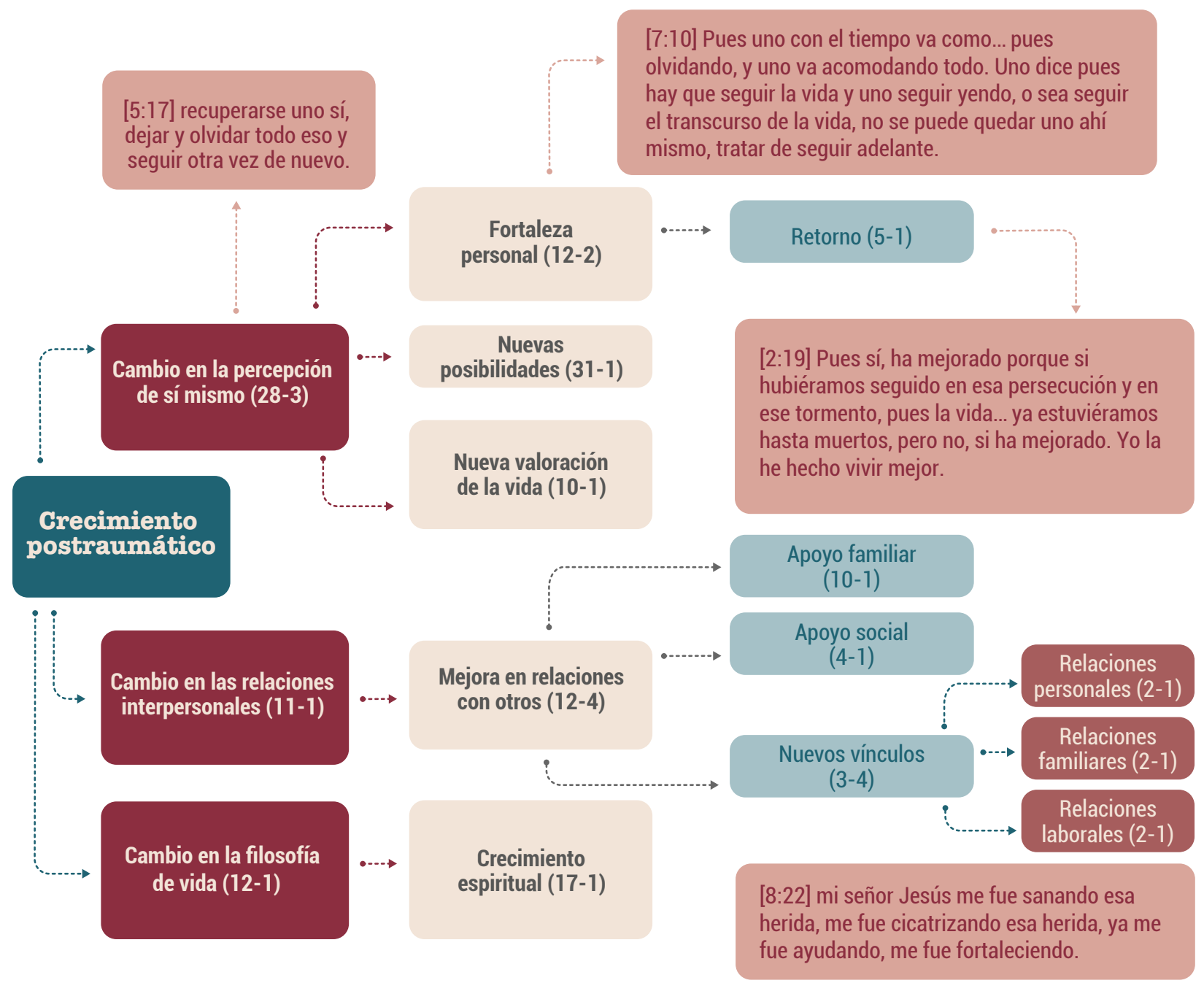

Figura 3. Crecimiento postraumático.

Fuente: elaboración propia.

En la categoría de cambio en la percepción de sí mismo, emergen las subcategorías de 1) fortaleza personal, 2) nuevas posibilidades y 3) nueva valoración de la vida. En la primera se evidencian seguridad, confianza, tranquilidad y fuerza de voluntad para enfrentarse a nuevas situaciones y experiencias de vida, plantean que se debe dejar en el pasado las vivencias traumáticas que experimentaron y emprender nuevos proyectos de vida. En el código de retorno, se postula que los participantes continuaron con las labores de pan coger y habitaron nuevamente las veredas o localidades de donde habían sido desplazados:

P2: «Nosotros estuvimos mucho tiempo por ahí así. Ya cuando vimos que en Guaduas ya la cosa estaba como más calmada, entonces nos regresamos para allá otra vez».

P8: «Ya no está uno mirando. Ya uno no está recordando ese momento tan triste de verlos bien tranquilos, sino que 
consiguió como esa paz y una tranquilidad para el alma que uno anhelaba y que lo necesitaba».

En la segunda subcategoría, se genera la disposición para desempeñarse con sus experiencias en nuevas actividades, también la destreza de aprovechar y adquirir nuevos conocimientos para transformar oportunidades en proyectos a corto, mediano y largo plazo; en la tercera postulan la valoración de situaciones que no eran percibidas como importantes; asimismo, encuentran aspectos positivos del hecho victimizante frente a la apreciación de seguir con vida en un entorno donde se sienten seguros y tranquilos:

P8: «Quiero irme a vivir a otro país, quiero irme, quiero irme, quisiera tener la experiencia de estar en otro país, como Estados Unidos, como Canadá. De hecho, he estado estudiando, he hecho unos cursos de inglés. De hecho, quiero estudiar inglés, porque en un futuro quiero irme a otro país a tener nuevas experiencias, nuevos retos, ya sea sola o con mi familia. Quiero irme para otro país a tener esa experiencia».

En la categoría de cambio en las relaciones interpersonales, emerge la subcategoría de mejora en relaciones con otros, se plantea la vocación a servir al núcleo familiar para que puedan desarrollar proyectos de vida que les brinde un futuro estable, la experiencia traumática generó en los participantes empatía y valoración de las personas que los rodean.

P12: «Mi vida cambió, o sea porque tengo un buen esposo, porque tengo ahora otros hijos, que han sido mi apoyo, y porque mi hijo mayor también ha sido un apoyo muy fundamental».
En el código nuevos vínculos, surgen los códigos relaciones personales, relaciones familiares y relaciones laborales, se halló la unión con personas nuevas con las que se estableció un hogar, también el concebir nuevos miembros en el núcleo familiar y el acercamiento a personas externas para que se les brindara una oportunidad laboral:

P5: «Pues el plan, y el deseo mío, es que mi papá salga de sus deudas, obviamente ayudarle de una u otra manera, y pues con la ayuda de Dios que salga de sus deudas, eso es lo primordial».

P7: «Como a los dos años fue que ya aquí, pues ya conseguí novia acá en el pueblo y ya me casé».

P11: «Esa situación que pasó le sirvió de enseñanzas a uno para poder valorar como las personas, mirar y ayudar a alguien que de pronto está en un lugar equivocado y que uno no miró esa forma y esa persona para ayudarlo a salir de esa situación».

Por último, en la categoría de cambio en la filosofía de vida, emerge la subcategoría crecimiento espiritual, se plantea el cambio o fortalecimiento religioso e ideológico de los participantes en su espiritualidad, se evidencia que el foco de su vida lo han entregado totalmente a Dios y al evangelio para vivir de una manera más tranquila, separados del odio y el rencor para con los actores armados que vulneraron sus derechos y atentaron contra la vida de sus familiares. De igual manera, se evidencia que la espiritualidad los alejó de tomar venganza para los mismos y que la vida es mejor desde que Dios hace presencia en sus vidas, porque él les permite seguir el día a día, tienen toda la confianza puesta en él para culminar su vida de su mano: 
P4: «Dios me da y Dios nos ha guardado también. Dios nos ha guardado de muchas cosas. Porque a mí me decían que no me viniera para acá, que aquí iba a haber un combate y yo dije: "Que va si nosotros tenemos la ayuda de Dios, que Dios nos guarda". Y sí, porque cada rato nos decían: "Váyanse de acá porque es aquí donde llega tanta gente", y yo les dije que no: "Es que nosotros tenemos la confianza en Dios"».

P11: «Tuve muchas dificultades luchando contra la venganza. Siempre le llega el pensamiento de buscar venganza. Pero uno, la biblia dice que "mía es la venganza". Y yo me aferraba a él, a ese mandamiento, y a luchar contra eso. Si no hubiera estado en el evangelio, yo hasta hubiera caído en algún grupo a buscar venganza, pero gracias a Dios estaba en el buen camino».

\section{Discusión}

Como se ha evidenciado, el desplazamiento forzado en El Carmen de Atrato es un hecho victimizante concurrente que se genera debido al conflicto armado, donde las comunidades afectadas se han visto en la obligación de abandonar sus territorios, dejando de lado sus tierras, actividades económicas, culturales y bienes inmuebles, debido a las diferentes estrategias militares, presión y presencia de los grupos armados en las zonas en que estaban ubicados.

El desplazamiento forzado ha impedido que la población tenga la posibilidad de estar en un entorno en el cual su vida adquiera sentido, tal como lo plantea Jaimes (2014) respecto a la tranquilidad y libre desarrollo, en donde también se afecta el núcleo familiar. Respecto al último concepto se encontró que las nuevas dinámicas a las que se enfrentaron los individuos produjeron una ruptura del núcleo familiar, al generarse nuevas estrategias de subsistencia, al verse privados de las necesidades básicas y perder la autodeterminación económica por depender de familiares $\mathrm{u}$ otros individuos. Este hecho genera en las personas un daño o trauma psicológico, en el cual las diferentes situaciones en las que se ven enfrentados después del desplazamiento pueden ser percibidas como eventos traumáticos, y autores como Shakespeare-Finch y Copping (2006) postulan que al vivenciar una situación traumática puede producirse respuestas psicológicas, físicas y sociales.

En función de esto y en concordancia con Shakespeare-Finch y Copping (2006), el desplazamiento en las víctimas generó sentimientos de culpa y tristeza relacionado con la toma de decisiones frente a acciones no realizadas. Considerando que con el hecho de haber actuado podrían haber evitado el desplazamiento o los homicidios de familiares y personas de la comunidad, de igual manera, el enfrentarse a nuevos contextos donde se es excluido o percibido como amenaza, generó una visión negativa del mundo y un alejamiento social.

Sin embargo, los sucesos permitieron aprender del trauma y generar nuevas dinámicas y proyectos de vida. La nueva realidad a la que se enfrentaron los individuos permitió generar un proceso de reparación, el cual da respuesta a un crecimiento postraumático tal como lo plantean Tedeschi y Calhoun (2004). Estos 
autores lo definen como la capacidad que tiene una persona de generar cambios positivos luego de experimentar un evento traumático.

No obstante, aunque se encontró que las víctimas consideraban que su estilo de vida antes del desplazamiento era tranquilo, autosuficiente y no se percibía la posibilidad de la separación del núcleo familiar, se logra evidenciar que el suceso traumático generó nuevas habilidades, destrezas y oportunidades que no eran consideradas en su vida antes del desplazamiento. Incluso, de acuerdo con las historias, se demuestra el fortalecimiento personal, con el cual crece la seguridad y confianza para retornar a los territorios y transitar por zonas donde antes el miedo no les permitía tomar esa decisión.

Estos aspectos son definidos por Páez et al. (2008) como el cambio en la percepción de sí mismo, en el cual también se posibilita la fortaleza y la apreciación de la vida. Nuevos retos y formas de interacción se expresan desde el aprender y poner en práctica, en otros ámbitos, los conocimientos que ya hacían parte de su estilo de vida. Incluso las nuevas experiencias permitieron que adquirieran nuevas habilidades que los motivó a generar proyectos de vida, estos aspectos desarrollaron una nueva valoración de la vida, poniendo de manifiesto que, aunque vivieron situaciones que atentaron contra su integridad, su vida ha mejorado y son ellos quienes han generado estrategias para crecer en la posibilidad de mejor calidad de vida. Por su parte, los resultados de la investigación, realizada por Arias y García (2019) en sobrevivientes de un terremoto, evidenció que el cambio en la percepción de sí mismo fue mayor en personas chilenas en relación a las ecuatorianas, esto debido al predominante individualismo que se desarrolló en la población chilena, mientras que la ecuatoriana se caracterizó por pensar de manera colectiva.

Así pues, se evidencia que el apoyo social y familiar es denominado por las personas como un factor protector que permitió el afrontamiento y la disminución del estrés ante el evento traumático. También la planeación y ejecución de proyectos en pro de ayudar a las personas que se encuentran en su entorno y no han logrado resarcir los flagelos del desplazamiento. Estos resultados son similares al estudio de Aliche, Ifeagwazi, y Onyishi (2019), donde jóvenes sobrevivientes a un ataque terrorista a través de la presencia del apoyo social (familiares, amigos y personas importantes) lograron sobrellevar y percibir eventos traumático de una manera menos estresante, al igual que promover el CPT. Esta postura de acuerdo con Andrades (2016) se define como el cambio en las relaciones interpersonales. Las víctimas fortalecen las relaciones sociales, debido a que luego de experimentar un evento traumático nace en el interés de valorar y mejorar las relaciones con los otros, la empatía y la otredad, permite compartir social y vocación de servir a su entorno de forma constructiva.

Finalmente, las víctimas generaron cambio en su filosofía de vida, se evidencia transformación ideológica y crecimiento espiritual. Los autores Andrades (2016), Páez et al. (2008) mencionan que la idea que tienen los individuos frente al mundo desde lo moral, los valores y lo espiritual puede cambiar luego de una experiencia traumática. La investigación realizada por Romero (2018) demostró que el crecimiento espiritual es uno de las 
dimensiones con mayor crecimiento en víctimas del conflicto armado, el cual permite aumentar el nivel de perdón y reconciliación con sus victimarios a través de la espiritualidad.

Lo anterior se articula con las historias de vida de las víctimas, las cuales vigorosamente otorgan gran significado a Dios y a la iglesia a la que han pertenecido en los últimos años, el cual ha contribuido a la superación del miedo, la desconfianza y los pensamientos de venganza hacia los actores armados que irrumpieron la tranquilidad o la cotidianidad de sus vidas, por lo cual Dios constituye uno de los factores para la superación de sentimientos negativos.

P8: «Mi señor Jesús me reveló el evangelio. Leo mucho la biblia. Le oro muchos al señor y le pido a Dios que me ayude. Primeramente, Dios me ha ayudado, a no tenerles rencor, a no guardarles ese odio contra ellos. He estado en talleres de superación personal, me han ayudado mucho y el tiempo va ayudándolo a uno a cicatrizar esas heridas. Hoy por hoy, puedo decir que cien por ciento, me siento ya tranquila. Aunque todo eso no se olvida, esos malos momentos no se olvidan. Pero yo pienso que Dios tenía todo así, que tenía que pasar así».

Posterior al evento, las personas desarrollaron un crecimiento postraumático, el cual les ha permitido tener calidad de vida estable y tranquila en las zonas que están ubicadas actualmente. Por ello, se logra determinar que las dos dimensiones que se hallaron más impulsadas en el crecimiento son el cambio de percepción de sí mismo y el cambio en las relaciones interpersonales.

\section{Conclusiones}

Esta investigación estuvo orientada al análisis de las historias de vida en crecimiento postraumático de víctimas de desplazamiento forzado en El Carmen de Atrato-Chocó, en las cuales se evidenció una nueva visión del mundo y de sí mismos frente a cambios que se presentaron en cada uno de ellos. El análisis mostró que los cambios más significativos se manifestaban en la percepción de sí mismo y en las relaciones interpersonales. Los participantes desarrollaron confianza y fortaleza para enfrentarse a nuevas dinámicas y experiencias, que influyeron de manera notable en la decisión de retornar a los territorios, creando proyectos y metas que antes del desplazamiento no eran considerados. Estas nuevas posibilidades se convirtieron en dinámicas de aprendizaje activo de otras experiencias.

De igual forma, se encuentra que el apoyo social y familiar fue importante en el crecimiento, permitiendo que las personas que estaban a su alrededor les ayudaran o fueran un motivo para empezar a valorar o mejorar sus relaciones personales. En este sentido, también se evidenció un incremento de la calidad de vida en la medida en que las víctimas estuvieron rodeadas de personas que los apoyaron y se convirtieron en motivo para empezar un nuevo camino.

En relación con el cambio en la filosofía de vida, el desarrollo espiritual en los participantes influyó en su proceso de transformación de aquellos sentimientos o pensamientos negativos frente al sujeto o hecho victimizante, por aquellos cuya evocación fuese más positiva, es decir, la espiritualidad fue un aspecto 
determinante para el cambio de percepción del suceso victimizante y los involucrados en el mismo.

Los resultados de esta investigación permitieron describir las dinámicas y estilos de vida que llevaron a cabo los participantes antes, durante y después del evento traumático, al igual que los cambios que desarrollaron las personas luego del suceso traumático. Asimismo, se posibilitó conocer en las historias de vida los puntos críticos que llevaron al crecimiento postraumático, el cual se desarrolló en los participantes luego de estar localizados en la cabecera municipal y verse inmersos en situaciones que no eran habituales al estilo de vida, entre las que se encuentran: la desestabilidad económica, la pérdida de bienes inmuebles al salir de sus localidades y la afectación de la autodeterminación, la exclusión y rechazo, y el miedo.

Cabe mencionar, que la desestabilidad económica, por el hecho de tener que empezar de cero al desplazarse a un nuevo lugar, va ligada a la pérdida de bienes inmuebles, y a la falta de autodeterminación que es la condición de depender económicamente de personas externas para la propia subsistencia. Asimismo, la exclusión y rechazo que percibieron las personas por parte de los habitantes del municipio de El Carmen de Atrato al considerarlos el enemigo, es decir, ser etiquetados como guerrilleros o colaboradores. Por otro lado, las historias de vida pusieron en evidencia el miedo por parte de los entrevistados a verse enfrentados nuevamente a sucesos por parte de grupos al margen de la ley, ya que estos hechos victimizantes generaron inseguridad e intranquilidad en el interior de las comunidades.
Además, se logró analizar en las historias de vida de los participantes el desarrollo de crecimiento postraumático en las tres dimensiones planteadas; sin embargo, el cambio en la percepción de sí mismo y las relaciones interpersonales fue más significativo en los participantes que el cambio en la filosofía de vida. Esto frente a las nuevas dinámicas y estilos de vida que han encaminado y siguen construyendo hasta el momento, basadas en las fortalezas personales, nuevas oportunidades, apreciación de la vida, el apoyo familiar y social.

Finalmente, aunque los participantes durante la entrevista manifestaron pertenecer a una comunidad cristiana, el crecimiento espiritual no tuvo la misma relevancia en las historias de vida en relación con las otras dos dimensiones. Es necesario tener en cuenta que, para futuras investigaciones en el área, se debe ampliar el número de participantes con el objetivo de tener la posibilidad de comprender el fenómeno desde otros sucesos con igual nivel de complejidad.

\section{Referencias}

- Aliche, J. C., Ifeagwazi, C. M., \& Onyishi, I. E. (2019). Presence of Meaning in Life Mediates the Relations Between Social Support, Posttraumatic Growth, and Resilience in Young Adult Survivors of a Terror Attack Between Social Support . Journal of Loss and Trauma, 24(8), 1-14. https://doi.org/10.1080/15325024.2 019.1624416 
- Alvarán, S., García, M., y Gil, J. (2009). Desplazamiento forzado y proyecto de vida : un estudio de caso en Colombia. Universitat Jaume.

- Andrades, M. (2016). Trastorno de estrés postraumático y crecimiento postraumático en niños y adolescentes afectados por el terremoto del año 2016 en Chile. Universidad Complutense. Recuperado de http://eprints.ucm.es/38827/1/ T37651.pdf

- Arias-Gómez, J., Villasís-Keever, M., y MirandaNovales, M. (2016). El protocolo de investigación III: la población de estudio. Revista Alergia México, 63(2), 201-206. Recuperado de www.nietoeditores.com.mx

- Arias, P., y García, F. (2019). Crecimiento postraumático en sobrevivientes de los terremotos en ecuador y chile, 17, 317-331.

- Barberol, E., \& Linley, P. A. (2006). Posttraumatic growth, positive changes, and negative changes in madrid residents following the March 11, 2004, Madrid train bombings. Journal of Loss and Trauma, 17(5), 409-424. https://doi. org/10.1080/15325020600685519

- Bhor, S. (2017). Crecimiento postraumático en sobrevivientes del deslizamiento en la colonia el Cmbray II, Santa Catatina Pinula. Universidad Rafael Landívar. Recuperado de http:// recursosbiblio.url.edu.gt/tesiseortiz/2018/05/42/ Bhor-Silvia.pdf

- Breu, F., Guggenbichler, S., y Wollmann, J. (2008). La Investigación Cualitativa. Vasa, 1. Recuperado de http://medcontent.metapress.com/index/ A65RM03P4874243N.pdf

- Campos, M. (2013). Creciendo en la adversidad. Una revisión del proceso de adaptación al diagnóstico de cáncer y el crecimiento postraumático. Escritos de Psicología / Psychological Writings, 6(1), 6-13. https://doi. org/10.5231/psy.writ.2012.2109

- Contreras, J. (2003). El conflicto armado en colombia. Revista de Derecho, Universidad Del Norte, 19(19), 119-125. https://doi.org/26305995
- Corporación Humanas. (2019). Derechos humanos de las mujeres Chocoanas, una cuestión de Estado. Revista de estudios de género: La ventana, 2. Bogotá. Recuperado de https://bit.ly/38tygfA

- Costa, G., y Gil, F. L. (2008). Respuesta cognitiva y crecimiento postraumático durante el primer año de diagnóstico del cáncer. Psicooncología, 5, 27-37. Recuperado de https://bit.ly/2DPF5tS

- Cruz, L. (2012). Posibles deconstrucciones del trauma. Una aproximación posmoderna. Revista de Sociedad \& Equidad, 3

- Esparza, T., Martínez, T., Leibovich de Figueroa, N., Campos, R., y Lobo, A. (2015). Estudio longitudinal del crecimiento postraumático y la calidad de vida en mujeres supervivientes de cáncer de mama. Psicooncologia, 12(2-3), 303314. https://doi.org/10.5209/rev

- Ibáñez, A., \& Velásquez, A. (2008). El impacto del desplazamiento forzoso en Colombia: condiciones socioeconómicas de la población desplazada, vinculación a los mercados laborales y políticas públicas. CEPAL - Serie Políticas sociales, (145).

- Jaimes, J. (2014). El desplazamiento forzado en Colombia. Anales de La Cátedra Francisco Suárez, 48, 257-275.

- Maldonado, P., Cova, F., Bustos, C., y García, F. (2014). Afrontamiento y rumiación frente a eventos adversos y crecimiento postraumático en estudiantes universitarios. Liberabit, 20(2), 281-292.

- Martínez-salgado, C. (2012). El muestreo en investigación cualitativa. Principios básicos y algunas controversias. Ciencia \& Salúde Colectiva, 17(3), 613-619. Recuperado de http:// www.scielo.br/pdf/csc/v17n3/v17n3a06.pdf

- Obando, L., Viscaya, Y., y Fernández, M. (2016). Conflicto armado, problemática de poderes que ha vulnerado a la sociedad colombiana. Katharsis, 21, 385-417. Recuperado de http:// revistas.iue.edu.co/index.php/katharsis 
- Otzen, T., y Manterola, C. (2017). Técnicas de Muestreo sobre una Población a Estudio. International Journal of Morphology, 35(1), 227-232. https://doi.org/10.4067/ S0717-95022017000100037

- Páez, D., Beristain, C., Gonzales-Castro, J., Basabe, N., y de Rivera, J. (2011). Crecimiento post estrés y post-traumático: posibles aspectos positivos y beneficiosos de la respuesta a los hechos traumáticos. En Superando la Violencia Colectiva y Construyendo Cultura de Paz (pp. 311-339). Madrid: Editorial Fundamentos Colección Ciencia.

- Páez, D., Bilbao, M., \& Javaloy, F. (2008). Del trauma a la felicidad: Los hechos negativos extremos pueden generar creencias positivas y crecimiento personal. En M. Martina Casullo (Ed.), Prácticas en Psicología Positiva (pp. 1-29). Buenos Aires: Lugar Editorial.

- Quecedo, R., y Castaño, C. (2003). Introducción a la metodología de investigación cualitativa. Revista de Psicodidáctica, (14), 5-40. Recuperado de http://dialnet.unirioja.es/servlet/ articulo?codigo $=739292$

- Registro Único de Víctimas. (2019a). Reporte general. Recuperado de https://bit.ly/33T0kW7

- Registro Único de Víctimas. (2019b). Reporte hechos victimizantes. Recuperado de https://bit. ly/34VizLX

- Rojas, J. C. (2016). Etapas del conflicto armado en Colombia: hacia el posconflicto. Latinoamérica. Revista de Estudios Latinoamericanos, 62(62), 227-257. https://doi. org/10.1016/j.larev.2016.06.010
- Romero, J. (2018). Propiedades psicométricas de las escalas GHQ-12, CPTI y ESRV aplicadas en el contexto del conflicto armado colombiano. International E-Journal of Criminal Science, 12(3), 1-26.

- Sandoval, C. A. (2002). Investigación cualitativa. (AFRO, Ed.). Bogotá: Programa de Especialización en Teoría, Métodos y Técnicas de Investigación Cualitativa.

- Serra-Horhuelin, A., \& Schoeller-Díaz, D. A. (2014). Chocó: entre la extracción y el olvido. Uniclaretiana.

- Shakespeare-Finch, J., \& Copping, A. (2006). A grounded theory approach to understanding cultural differences in posttraumatic growth. Journal of Loss and Trauma, 17(5), 355-371. https://doi.org/10.1080/15325020600671949

- Tawse-Smith, D. (2008). Conflicto armado colombiano. Desafíos, 19, 270-299. https://doi. org/39764007

- Tedeschi, R. G., \& Calhoun, L. C. (2004). Posttraumatic growth: Conceptual foundations and empirical evidence. Psychological Inquiry, 15(1), 1-18

- Tedeschi, R. G., \& Calhoun, L. G. (1996). The posttraumatic growth inventory: Measuring the positive legacy of trauma. Journal of Traumatic Stress, 9(3), 455-471. https://doi.org/10.1002/ jts. 2490090305 